\title{
HYPERVENTILATION IN ARTERIOLAR HYPERTENSION
}

\author{
By SAMUEL H. PROGER AND DAVID AYMAN
}

(From the Medical Clinic, Boston Dispensary, Service of Dr. Joseph H. Pratt, Boston)

(Received for publication October 27, 1932)

Raab (1), in a study dealing with the effect of hyperventilation on the blood pressure of patients with arteriolar hypertension, concluded that there is a direct and constant relationship between the level of the blood pressure in patients with essential hypertension and the extent to which the $\mathrm{CO}_{2}$ tension of the arterial blood (alveolar $\mathrm{CO}_{2}$ tension) is lowered. The assumption was that hyperventilation produced lowering of the blood pressure in people with essential hypertension because of lowering of the $\mathrm{CO}_{2}$ content of the blood. ${ }^{1}$

Previous to this work many physiologists had studied the effect of hyperventilation on people with normal arterial tension and in animals. Their methods differed so much from those of Raab and those presented here that comparisons are perhaps unjustifiable. Their results, however, are significant. Vincent and Cameron (2) in 1915 showed that hyperventilation in the human subject with normal blood pressure was associated with a rapid and considerable fall in blood pressure. This work confirmed earlier observations by Hill and Flack (3) and by Boothby (4). Collier, Densham, and Wells (5) found no effects of hyperventilation on the blood pressure of most of their human subjects with normal blood pressures. They thought that the systolic blood pressure was maintained nearly constant by means of a compensating cutaneous vasoconstriction. Schneider (6) agreed with this view. Vincent and Thompson (7) found that 37 out of $\mathbf{4 1}$ normal subjects showed a fall in blood pressure during a short period of hyperpnea. They suggested that the falls in blood pressure are due to mechanical interference with the return of blood to the heart, and that the lowered $\mathrm{CO}_{2}$ tension of the blood is only a subsidiary factor.

In this study, an attempt has been made further to evaluate the significance of the $\mathrm{CO}_{2}$ factor in the blood in essential hypertension. Also in our subjects with hypertension, the effect of hyperventilation on the cardiac output, the pulse rate, and on the vital capacity of the lungs was observed.

${ }^{1}$ Recently Corbini has been unable entirely to confirm these views. (Corbini, G.: Effetti della iperventilazione polmonare sulla pressione sanguigna. Riforma med. 1932, 1167-1173). 
Seven patients were studied. In each case, blood pressure readings had been taken on numerous visits to the clinic before these studies were undertaken, so that we were thoroughly familiar with the variations and fluctuations in the blood pressure levels to which these patients were subject. The experimental periods were repeated several times on separate days in each case, not only to obtain satisfactory checks, but also to note possible daily variations. The effect of hyperventilation on the blood pressure of three normal people was observed also.

The patients were all women between the ages of thirty-five and sixty. In each case the diagnosis was essential hypertension. There was no evidence of heart failure or pulmonary disease in any patient. The pertinent facts concerning the status of the cardiovascular system in the individual patients are given in Table $I$. In all patients the following special tests and examinations were made: Electrocardiogram, orthodiagram of the heart, careful examination of fundus oculi, dilution and concentration test and phenolsulphonphthalein excretion test for kidney function. Also the percentages of nonprotein nitrogen and urea nitrogen in the blood were determined.

\section{METHOD}

The patients sat in a chair in a comfortable position. They were allowed to sit quietly with mouthpiece, nose-clip, and blood pressure cuff attached until the blood pressure reached a resting level. A determination of the cardiac output was then made, using the acetylene method of Grollman (8). A sample of the alveolar $\mathrm{CO}_{2}$ at rest was obtained at the same time, and the vital capacity was measured. It was possible to carry out all of these procedures without disturbing the patient. A three-way valve was used. The patient thus could breathe first into a spirometer (125 liters Tissot) where air could be collected for determinations of metabolism. Then the patient could expire through another opening of the valve into a tube in the middle of which (about $40 \mathrm{~cm}$. from mouthpiece) was a one-way flap valve. From the beginning of this tube an alveolar sample was collected. Connected to this tube beyond the flap valve was a small spirometer for measuring vital capacity. On the third opening of the three-way valve was a balloon, to which the patient could be switched at will, containing the acetylene mixture which was used for the estimation of the arteriovenous oxygen difference.

Patients were constantly urged to breathe deeply in and out during the hyperventilation. The rate of breathing was the same in all cases, being timed by a metronome. The hyperventilation was continued four to twenty-five minutes. The rate of the pulse and the level of the blood pressure were observed every one to two minutes, and alveolar samples were collected every three to five minutes. Where the level of the blood pressure and the value of the alveolar $\mathrm{CO}_{2}$ are recorded at the same time, 


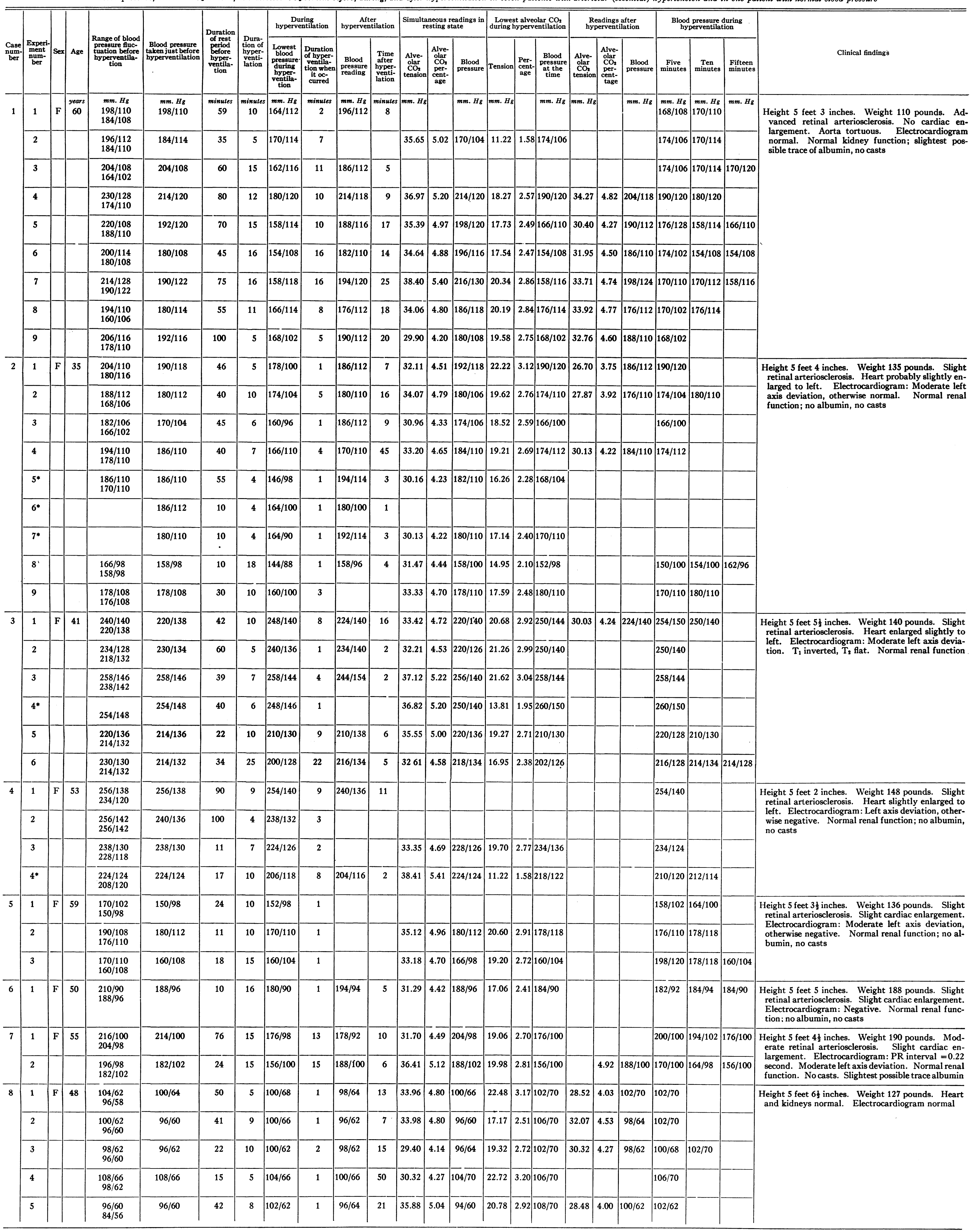


the reading of the blood pressure was always made immediately before the alveolar $\mathrm{CO}_{2}$ samples were collected so that the exertion of the complete expiration did not influence the level of the blood pressure. Breathing of the three per cent $\mathrm{CO}_{2}$ mixture was from the 125 liter Tissot spirometer.

\section{RESULTS}

Hyperventilation and blood pressure. There was no uniformity of results (Table I). There was a considerable drop in blood pressure in only 3 of the 7 patients studied; in 2 there was only a slight drop; in 1 patient there was no drop; and in the remaining patient the blood pressure usually rose with hyperventilation. The duration of the period of hyperventilation did not change these results significantly. Sometimes more rapid hyperpnea caused a greater drop in blood pressure. In the three normal persons no definite changes occurred in the blood pressure following hyperventilation. The result of hyperventilation in a person with normal blood pressure is shown in Table I. The other two people with normal blood pressure also showed no effect. The periods of hyperventilation ranged from 4 to 25 minutes. The respiratory rates were fixed at 18 or 28 per minute.

In all of the patients a considerable drop could have been recorded had the readings been taken only at the end of inspiration. The effect of a single inspiration or expiration on the blood pressure is well known and is probably to be attributed to the mechanical effect of sudden changes in intrathoracic pressure. Considerable fluctuation in the levels of the blood pressure was observed during the various phases of single respirations, and accurate readings were therefore difficult to obtain. Whenever possible, double values were recorded for the blood pressure at the various stages of a single respiration. When the fluctuations were not marked and single readings are recorded, these readings represent the first point at which the sounds came through. It is possible that in those cases in which little or no fall in blood pressure is recorded, a fall might have occurred which was obscured by a rise due to the excitement and exertion of the hyperventilation. In order to overcome the emotional reaction as a disturbing factor, the procedure was repeated several times until it appeared reasonably certain that little or no excitement attended the process of deep breathing. The physical exertion was so slight as not to be of considerable importance. The extent of the work is indicated by the fact that in three of the cases in which the oxygen consumption was measured before and during hyperventilation, there was an average rise only from $200 \mathrm{cc}$. of oxygen per minute to $260 \mathrm{cc}$. of oxygen per minute.

As can be seen from Table I, there was usually considerable spontaneous fluctuation in the blood pressures during the resting stage preceding the periods of hyperventilation. Hyperventilation was not always begun just when the blood pressure reached the lowest resting level. Thus in 
some instances in which a drop is observed during hyperventilation, there was no drop from the lowest resting level. Since spontaneous variations occur so regularly in the resting periods, it is not unreasonable to assume that they occur also during the periods of hyperventilation. The lowest blood pressure reached during hyperventilation, then, may be in part due to a spontaneous fall in some instances. This assumption is borne out especially by the fact that the lowest blood pressure during hyperventilation usually persisted only one or two minutes.

It was not an uncommon occurrence for the blood pressure to reach its lowest level during the first one to three minutes of hyperventilation, and then gradually rise again. In some instances, on the other hand, it was only after several minutes of hyperventilation that a change was observed. There was considerable and irregular variation in the manner of reaction in this as in most studies dealing with people who have essential arteriolar hypertension.

Alveolar $\mathrm{CO}_{2}$ and blood pressure. No definite relationship was observed between the lowering of the alveolar $\mathrm{CO}_{2}$ tension, and the drop in blood pressure. For example, in Case 2 in which there was some drop with hyperventilation, the blood pressure was $180 / 106$ during rest and the alveolar $\mathrm{CO}_{2}$ tension was $34.07 \mathrm{~mm}$. $\mathrm{Hg}$ (alveolar $\mathrm{CO}_{2}$ content 4.79 per cent). After hyperventilation for five minutes, the blood pressure had dropped only to $174 / 104$, although the alveolar $\mathrm{CO}_{2}$ tension was now $22.25 \mathrm{~mm}$. $\mathrm{Hg}$ (alveolar $\mathrm{CO}_{2}$ content 3.13 per cent). With nine minutes hyperventilation, the blood pressure was still $174 / 110$, while the alveolar $\mathrm{CO}_{2}$ tension had dropped to $19.62 \mathrm{~mm}$. $\mathrm{Hg}$ (alveolar $\mathrm{CO}_{2}$ content 3.92 per cent). Ten minutes after the hyperventilation, the blood pressure was practically the same, 176/110, and yet the alveolar $\mathrm{CO}_{2}$ tension had risen to $27.87 \mathrm{~mm}$. $\mathrm{Hg}$ (alveolar $\mathrm{CO}_{2}$ content 3.92 per cent).

The view might be held that possibly a delay occurs in the reaction of the blood pressure to the drop in alveolar $\mathrm{CO}_{2}$ tension, and that if the alveolar $\mathrm{CO}_{2}$ tension were kept low long enough, the blood pressure would drop. This was found not to be true. If the drop in blood pressure took place, it was almost simultaneous with the drop in the alveolar $\mathrm{CO}_{2}$ tension; if it did not occur, a long continued hyperventilation with a subsequent lowering of the alveolar $\mathrm{CO}_{2}$ tension did not produce it. Thus, in Case 6, the alveolar $\mathrm{CO}_{2}$ tension at rest was $31.29 \mathrm{~mm}$. $\mathrm{Hg}$ (alveolar $\mathrm{CO}_{2}$ content 4.42 per cent), and the blood pressure at rest 188/96. After hyperventilation for three minutes the alveolar $\mathrm{CO}_{2}$ tension was 21.88 $\mathrm{mm}$. $\mathrm{Hg}$ (alveolar $\mathrm{CO}_{2}$ content 3.09 per cent), and the blood pressure 180/92. At the end of seven minutes, alveolar $\mathrm{CO}_{2}$ tension was 18.69 mm. $\mathrm{Hg}$ (alveolar $\mathrm{CO}_{2}$ content 2.64 per cent), blood pressure 184/94. At the end of eleven minutes alveolar $\mathrm{CO}_{2}$ tension was $17.70 \mathrm{~mm} . \mathrm{Hg}$ (alveolar $\mathrm{CO}_{2}$ content 2.5 per cent), blood pressure 184/94; and at the end of fifteen minutes alveolar $\mathrm{CO}_{2}$ tension was $17.06 \mathrm{~mm}$. $\mathrm{Hg}$ (alveolar $\mathrm{CO}_{2}$ content 
2.4 per cent), and blood pressure 184/90. In other words, while the alveolar $\mathrm{CO}_{2}$ tension was quickly and considerably lowered by hyperventilation, and remained so for fifteen minutes, the blood pressure was never lowered. The same was true in the other case in which no effect was produced on the blood pressure by hyperventilation (Case 5), the blood pressure just before hyperventilation being $160 / 108$, whereas after fifteen minutes hyperventilation it was $160 / 104$, although several samples showed the alveolar $\mathrm{CO}_{2}$ tension to be distinctly low throughout this period of hyperventilation.

This question naturally arose: Were the differences in the response of the blood pressure to lowering of alveolar $\mathrm{CO}_{2}$ due to differences in sensitivity of the vasomotor centers to the $\mathrm{CO}_{2}$ tension of the arterial blood? That is, was the vasomotor center in Case 1 (in which blood pressure dropped considerably) more sensitive to the $\mathrm{CO}_{2}$ tension in the arteries than the vasomotor center in the cases in which the blood pressure did not fall with the drop in $\mathrm{CO}_{2}$ tension? It was thought that these differences in sensitivity, if they occurred, could be observed simply by noting the response of the blood pressure when a mixture containing 5 per cent $\mathrm{CO}_{2}$ was breathed quietly. During such a procedure the blood pressure rose in Case 1 from 174/104 in six minutes to 214/122; whereas in Case 6, in which a drop in alveolar $\mathrm{CO}_{2}$ tension did not produce a drop in blood pressure, the blood pressure rose in six minutes from 220/120 to 264/138. In other words, each patient seemed equally sensitive to $\mathrm{CO}_{2}$ as determined by the response of the blood pressure to quiet breathing of a constant mixture of five per cent $\mathrm{CO}_{2}$, and yet a lowering of the $\mathrm{CO}_{2}$ tension of the arterial blood produced quite different responses of the blood pressure in each case. It would seem, therefore, unjustifiable to assume that in those cases of essential hypertension in which hyperventilation with subsequent lowering of the tension of the arterial $\mathrm{CO}_{2}$ produces a large drop in blood pressure, a greater sensitivity to $\mathrm{CO}_{2}$ exists. The fact that more rapid hyperpnea without more marked drop in arterial $\mathrm{CO}_{2}$ tension sometimes produced greater lowering of the blood pressure also militates against the idea that the drop is related simply to a sensitivity of the vasomotor center to $\mathrm{CO}_{2}$.

The chief argument of those who favor the view that it is the lowering of the $\mathrm{CO}_{2}$ tension alone which is responsible for the drop in blood pressure is that the blood pressure will not drop when the alveolar $\mathrm{CO}_{2}$ tension is maintained at a normal level during hyperventilation by the use of a mixture containing an excess of $\mathrm{CO}_{2}$. It is contended that if the drop in blood pressure were due to a mechanical factor, this drop would also be observed when the alveolar $\mathrm{CO}_{2}$ was maintained at a normal level, the mechanical factors remaining unchanged. However, an air mixture containing enough $\mathrm{CO}_{2}$ to maintain the alveolar $\mathrm{CO}_{2}$ at a normal level (about 3 per cent in our studies) contains enough $\mathrm{CO}_{2}$ to act in itself as an 
abnormal stimulus to the vasomotor center and thus raise the blood pressure (Van Esveld (9)). In cases in which the blood pressure apparently does not drop with hyperventilation, using a 3 per cent $\mathrm{CO}_{2}$ mixture, it may well be that the drop is obscured by a rise due to the stimulating effect of $\mathrm{CO}_{2}$. What seems like no effect then is probably a double effect in which there is a drop balanced by a rise. The following results make this assumption seem indeed likely. In Case 1, in which simple hyperventilation with lowering of the alveolar $\mathrm{CO}_{2}$ tension was accompanied by a definite drop in blood pressure, hyperventilation for five minutes with three per cent $\mathrm{CO}_{2}$ mixture produced no drop. The blood pressure at rest was $184 / 108$, and the alveolar $\mathrm{CO}_{2}$ tension was $33.02 \mathrm{~mm}$. $\mathrm{Hg}$ (alveolar $\mathrm{CO}_{2}$ content 4.65 per cent); the blood pressure after the hyperventilation with three per cent $\mathrm{CO}_{2}$ was $184 / 110$, and the alveolar $\mathrm{CO}_{2}$ tension remained at the high level of $29.39 \mathrm{~mm}$. $\mathrm{Hg}$ (alveolar $\mathrm{CO}_{2}$ content 4.14 per cent). If it were assumed that hyperventilation in this case caused a drop in blood pressure which was balanced by a rise due to the air mixture containing three per cent $\mathrm{CO}_{2}$, then in a case where similar sensitivity to $\mathrm{CO}_{2}$ existed and in which simple hyperventilation produced little or no drop, hyperventilation with a three per cent $\mathrm{CO}_{2}$ mixture should cause the blood pressure to rise. Case 2 affords such an instance. Here, while there was on several occasions only a slight drop in blood pressure with simple hyperventilation at a respiratory rate of 18 per minute, the blood pressure rose from $170 / 108$ to $194 / 120$ after 4.25 minutes hyperventilation at the same rate with three per cent $\mathrm{CO}_{2}$, and the alveolar $\mathrm{CO}_{2}$ tension remained practically unchanged. In this case only the blood pressure raising effect of the $\mathrm{CO}_{2}$ was present; so a rise was recorded. In the two cases just compared, quiet breathing of a five per cent $\mathrm{CO}_{2}$ mixture produced similar rises in blood pressure indicating that the vasomotor centers were equally sensitive to $\mathrm{CO}_{2}$. The chief argument in favor of the role of $\mathrm{CO}_{2}$ in the lowering of the blood pressure in hyperventilation, namely, that when the alveolar $\mathrm{CO}_{2}$ is maintained at a normal level, the hyperventilation does not produce a drop in blood pressure, would thus seem to be untenable, since the two cases above indicate that a drop does occur which is balanced by a rise due to the extraneous factor of breathing a mixture containing an excess of $\mathrm{CO}_{2}$.

Hyperventilation and cardiac output. In three of the cases studied, estimations of cardiac output were made before and during hyperventilation. In one of these cases there was no change in blood pressure with hyperventilation; in one, a slight fall; and in one, a moderate fall. In the first of these cases the output of blood from the heart was practically unchanged during hyperventilation. In the other two there was somewhat of an increase (see Table II). The figures show in general what Grollman (10) found in normal people; namely, that the cardiac output increases to just about the extent which might be expected simply from 
TABLE II

Hyperventilation and cardiac output

\begin{tabular}{|c|c|c|c|c|c|c|c|c|c|}
\hline $\begin{array}{c}\text { Case } \\
\text { num- } \\
\text { ber }\end{array}$ & $\begin{array}{c}\text { Duration } \\
\text { of } \\
\text { hyper- } \\
\text { ventila- } \\
\text { tion }\end{array}$ & $\begin{array}{c}\text { Blood } \\
\text { pressure } \\
\text { before } \\
\text { hyper- } \\
\text { ventila- } \\
\text { tion }\end{array}$ & $\begin{array}{c}\text { Lowest } \\
\text { blood } \\
\text { pressure } \\
\text { during } \\
\text { hyper- } \\
\text { ventila- } \\
\text { tion }\end{array}$ & $\begin{array}{c}\text { Oxygen } \\
\text { con- } \\
\text { sumption } \\
\text { during } \\
\text { rest }\end{array}$ & $\begin{array}{l}\text { Arterio- } \\
\text { venous } \\
\text { oxygen } \\
\text { difference } \\
\text { at rest }\end{array}$ & $\begin{array}{l}\text { Cardiac } \\
\text { output } \\
\text { at rest }\end{array}$ & $\begin{array}{l}\text { Oxygen } \\
\text { con- } \\
\text { sumption } \\
\text { during } \\
\text { last } \\
\text { minute } \\
\text { of hyper- } \\
\text { ventila- } \\
\text { tion }\end{array}$ & $\begin{array}{l}\text { Arterio- } \\
\text { venous } \\
\text { oxygen } \\
\text { difference } \\
\text { at end of } \\
\text { hyper- } \\
\text { ventila- } \\
\text { tion }\end{array}$ & $\begin{array}{l}\text { Cardiac } \\
\text { output } \\
\text { at end of } \\
\text { hyper- } \\
\text { ventila- } \\
\text { tion }\end{array}$ \\
\hline & minutes & mm. $\mathrm{Hg}$ & $m m . H g$ & $c c$. & $\begin{array}{c}\text { cc. per } \\
\text { liter }\end{array}$ & liters & $c c$. & $\begin{array}{c}c c \text { per } \\
\text { liter }\end{array}$ & liters \\
\hline 3 & 10 & $214 / 140$ & $210 / 130$ & 194 & 77.34 & 2.5 & 242 & 105.2 & 2.3 \\
\hline 2 & 7 & $186 / 110$ & $174 / 112$ & 181 & 53.37 & 3.4 & 278 & 62.32 & 4.5 \\
\hline 7 & 7 & $182 / 98$ & $164 / 96$ & 227 & 53.11 & 4.3 & 260 & 50.85 & 5.1 \\
\hline
\end{tabular}

TABLE III

Hyperventilation and vital capacity

\begin{tabular}{|c|c|c|c|c|c|c|}
\hline $\begin{array}{c}\text { Case } \\
\text { number }\end{array}$ & $\begin{array}{l}\text { Experiment } \\
\text { number }\end{array}$ & $\begin{array}{l}\text { Vital capacity } \\
\text { at rest before } \\
\text { hyperventilation }\end{array}$ & $\begin{array}{c}\text { Vital capacity } \\
\text { during } \\
\text { hyperventilation }\end{array}$ & Time & $\begin{array}{l}\text { Vital capacity } \\
\text { at rest after } \\
\text { hyperventilation }\end{array}$ & Time \\
\hline \multirow[t]{5}{*}{2} & 1 & $\begin{array}{c}c c . \\
2700 \\
2800\end{array}$ & $\begin{array}{c}c c . \\
3000 \\
2950\end{array}$ & $\begin{array}{c}\text { minutes } \\
5 \\
13\end{array}$ & $c c$. & minutes \\
\hline & 2 & 2850 & $\begin{array}{l}2900 \\
2950\end{array}$ & $\begin{array}{r}6 \\
12\end{array}$ & 2825 & 11 \\
\hline & 3 & 3050 & 3050 & 4 & & \\
\hline & 4 & $\begin{array}{l}3100 \\
3000\end{array}$ & $\begin{array}{l}2950 \\
2925\end{array}$ & $\begin{array}{l}7 \\
4\end{array}$ & 3000 & 60 \\
\hline & 5 & 3000 & $\begin{array}{l}2850 \\
2900 \\
2800 \\
2950\end{array}$ & $\begin{array}{r}4 \\
6 \\
8 \\
18\end{array}$ & & \\
\hline \multirow[t]{5}{*}{3} & 1 & 2150 & $\begin{array}{l}1700 \\
1600\end{array}$ & $\begin{array}{r}6 \\
10\end{array}$ & 2150 & 15 \\
\hline & 2 & $\begin{array}{l}2300 \\
2350\end{array}$ & 2350 & 5 & & \\
\hline & 3 & 2400 & 2450 & 5 & & \\
\hline & 4 & 1800 & $\begin{array}{l}2050 \\
1950\end{array}$ & $\begin{array}{r}3 \\
10\end{array}$ & 2350 & 6 \\
\hline & 5 & 2350 & $\begin{array}{l}2250 \\
2200 \\
2200 \\
1750 \\
2200\end{array}$ & $\begin{array}{r}5 \\
10 \\
14 \\
18 \\
24\end{array}$ & & \\
\hline
\end{tabular}


the increase in work. The average increase in oxygen consumption was from $201 \mathrm{cc}$. per minute to $260 \mathrm{cc}$. per minute. In two of the cases, the arteriovenous oxygen difference increased, while in the third it remained almost unchanged.

Vital capacity. On the assumption that changes in blood volume within the lungs during hyperventilation, if present, might reflect themselves in changes in the vital capacities, the vital capacities were obtained before, during, and at the end of varying periods of hyperventilation. No definite changes in the vital capacities were observed. Two illustrative cases are presented in Table III.

Pulse rate. Hyperventilation was found to have no regular effect on the pulse rate. Sometimes there was no change in the pulse rate; sometimes there was slight slowing; more commonly there was a slight increase in the rate.

\section{SUMMARY AND CONCLUSIONS}

1. Hyperventilation produces a lowering of the blood pressure in some patients with essential hypertension. A significant drop does not regularly occur. There may even be a slight rise.

2. There appears to be no direct and constant relationship between the height of the blood pressure in patients with essential arteriolar hypertension and the alveolar $\mathrm{CO}_{2}$ tension.

3. In those cases of essential hypertension in which lowering of the arterial $\mathrm{CO}_{2}$ tension by hyperventilation is accompanied by a definite drop in blood pressure, no undue sensitivity to $\mathrm{CO}_{2}$ exists (measured by response of blood pressure to breathing of a mixture containing an excess of $\mathrm{CO}_{2}$ ) as compared with those cases in which hyperventilation has no effect.

4. In patients in whom a significant drop in blood pressure occurs with lowering of alveolar $\mathrm{CO}_{2}$ tension by hyperventilation, there is no drop when the alveolar $\mathrm{CO}_{2}$ tension is maintained at a normal level during hyperventilation with a mixture containing three per cent $\mathrm{CO}_{2}$. Evidence is presented which suggests that the absence of a drop in blood pressure under such circumstances is due to the balancing of a fall in blood pressure from the mechanical effects of deep breathing and a rise from the vasoconstricting effect of the three per cent $\mathrm{CO}_{2}$.

5. The cardiac output increases during hyperventilation in patients with essential hypertension to the extent which might be expected simply from the slight increase in work

6. The vital capacity appears not to be significantly altered after varying periods of hyperpnea. This is true also of the rate of the pulse. 


\section{BIBLIOGRAPHY}

1. Raab, W., Ztschr. f. d. ges. exper. Med., 1929, lxviii, 337. Die Beziehung zwischen $\mathrm{CO}_{2}$-Spannung und Blutdruck bei Normalen und Hypertonikern.

2. Vincent, S., and Cameron, A. T., Quart. J. Exper. Physiol., 1915, ix, 45. Observations upon the Vaso-motor Reflexes.

3. Hill, L., and Flack, M., J. Physiol., 1910, xl, 347. The Influence of Oxygen Inhalations on Muscular Work.

4. Boothby, W. M., J. Physiol., 1912, xlv, 328. Absence of Apnea after Forced Breathing.

5. Collier, R. J., Densham, H. B. A. R., and Wells, H. M., Quart. J. Exper. Physiol., 1927, xviii, 291. The Influence of Respiratory Movements on the Cutaneous Circulation.

6. Schneider, E. C., Am. J. Physiol., 1930, xci, 390. A Study of Respiratory and Circulatory Responses to a Voluntary Gradual Forcing of Respiration.

7. Vincent, S., and Thompson, J. H., J. Physiol., 1928, lxvi, 307. The Effect of Hyper-respiration on the Blood Pressure in Man.

8. Grollman, A., Am. J. Physiol., 1929, lxxxviii, 432. The Determination of the Cardiac Output of Man by the Use of Acetylene.

9. Van Esveld, L. W., Arch. f. exper. Path. u. Pharmakol., 1930, cxlvii, 317. Pharmakologie des Vasomotorenzentrums; II. Mitteilung: Der Anteil des Herzens und Vasomotorenzentrums an durch neidrige $\mathrm{CO}_{2}$-Konzentrationen hervorgerufenen Blutdrucksteigerungen.

10. Grollman, A., Am. J. Physiol., 1930, xciv, 287. Physiological Variations in the Cardiac Output of Man. IX. The Effect of Breathing Carbon Dioxide, and of Voluntary Forced Ventilation on the Cardiac Output of Man. 